International Journal of Scholarly Papers for Media and Communications

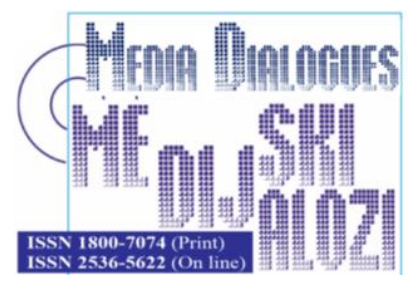

Rutovic, Z. (2021), „Globalization of Media - Globalization of the Problems (Challenges in Protection of Privacy)", Media Dialogues / Medijski dijalozi,

Vol. 14, No. 3, pp. 23-29.

\title{
Globalization of Media - Globalization of the Problems (Challenges in Protection of Privacy)
}

\author{
ZELJKO RUTOVIC, Msc \\ Montenegrin Ministry of Culture, \\ Podgorica, Montenegro
}

\begin{tabular}{|c|c|}
\hline $\boldsymbol{A} \boldsymbol{R} \boldsymbol{T} \boldsymbol{I} \boldsymbol{C L} \boldsymbol{E}$ & Received: January 22, 2021 / Revised from: February 24, 2021 \\
$\boldsymbol{I} \boldsymbol{N} \boldsymbol{F} \boldsymbol{O}$ & Accepted: March 24, 2020 / Available online: January 15, 2021 \\
\hline $\boldsymbol{D O I}$ & doi.org/10.14254/1800-7074/14-1/3 \\
\hline
\end{tabular}

\section{ABSTRACT}

The paper deals with the issue of protection of privacy in the media, low levels of self-regulatory ethical standards, dominance of profit in relation to ethical reporting. The paper gives an overview of the relevant documents as sources of protection of the rights of individuals in the media.

KEYWORDS: Privacy, human rights, media, legal protection. 


\section{INTRODUCTION}

The media are, among other things, products of distinct national history, culture, political situation, value orientation and ethical outlook of a society. The historical and cultural diversity necessarily generates differences in the understanding of and respect for the human rights concept. There have been many examples where the European continent experienced and went through turbulent periods because of ha- tred and lies published by the media. Regardless of all previous circumstances, the development of civilization and the lessons (not) learned, at the level of the global community, there is still an open and not less problematic question - how to find a balance between freedom of the media and respect for privacy rights?

For example, even in the cradle of democracy, due to violation of the right to privacy by a part of the British media, the Parliament in Westminster adopted the Human Rights Act in 1998, which requires the British courts to comply with the European Convention on Human Rights. When it took effect in 2000, privacy was finally incorporated into the British law. But despite everything, the events that led to the Leveson Inquiry (which referred to phone hacking of a murdered girl) and the attitudes that were disclosed during the investigation indicate that the disrespect of privacy still remains wide-spread among British tabloids. Hence, one of the key Levenson recommendations was that all employment contracts of journalists should contain a clause on freedom of consciousness.

That would imply a commitment by the employer that no journalist can be dismissed because he/she refused to violate this code. Of course, this example is only vividly showing that this is an obviously present problem, both in countries with long democratic tradition, and in those in transition, i.e. young democracies. What is paradoxical is the (multi)medial and civilizational shift in which the medium of message is transfigured into a medium of vices. Trends in the media industry, unauthorized concentration of economic ownership structure of media, convergence of platforms and overproduction of new technologies and distribution of contents via those that is illegal from the perspective of human rights, greatly complicates protection of the privacy panel of an individual.

\section{DISCUSSION}

In the globocentric capital industry everything is on the market, everything is purchased and sold. And there is often no clear regulation of such relations. Certainly, private life has long been a lucrative commodity, with different semantic contexts within which privacy becomes currency for the sake of ratings, listeners and readers of the media. The special exclusivity belongs to public figures and their private life. And the "ordinary" people are definitely not spared. Again, depending on whether there is sensationalism, spectacle, violence, gossip. Is there a balance to 
the torn poles of profit on one hand and more and more unprotected privacy on the other.

For this topic, let us quote the definition of a public figure, for which Recommendation no. 1165 (1998) in the narrow sense states that these are "persons holding public office and/or using public resources", and in the broader sense, "all those who play a role in public life, whether in politics, the economy, the arts, the social sphere, sport or any other domain". Although they should be subject to public scrutiny more than anonymous citizens, the European Court found that the politicians' privacy should be protected in cases where the sole purpose of publishing information from their private lives is to meet the in- terest of the public and to provide profitable material for the media (admissibility decision in the case of Société Prisma Presse v. France (application no. 66910/01 and 71612/01).

In the context of the definition of a public figure, protection of privacy, pub-ic interest and the interests of capital, there is a recurrent central question under this topic: is information a social public good or a commodity? Is the journalist accountable to the public or to the owner's capital? Does the journalist act in accordance with professional ethics or desirable capital aesthetics of the media founder?

Private life also includes the personal information of every individual for which he/she legitimately expects that they will not to be made public without his/her prior consent. The European Court of Human Rights found that the disclosure of information, which are true and represent actual events, may be prohibited on the account of the obligation to respect the right to privacy (Markt Intern Verlag $\mathrm{GmbH}$ and Klaus Beermann v Germany, 1989, p. 35). Invasion of privacy in the media is a situation where the published information concerns the private life of a person who has not consented to the disclosure, and at the same time there is no legal authority to publish such information.

Use of medical records i.e. information on health condition, private photographs, voice, private records and correspondence (diaries, letters, personal messages) represent invasion of privacy. Exceptionally, when there is prevailing broader public interest in publishing the information in relation to the individual right to privacy, this is a situation where exception to the right to privacy is made. But this is only an exception. Of course, we should bear in mind the need to balance public and private interests, and the exception should be subject to analysis through a test of potential harmfulness, which means that each individual case should be evaluated as separate and specific.

The vector analysis should focus here on the exempted practices recognized by the European Court of Human Rights. Interpretation of the relation of balance between the right to privacy and freedom of expression includes, of course, a lot of challenges and is still not fully and precisely defined in the European Court practice. 
The balance between the right to full information about the public figures, and in exceptional cases about ordinary people, and the rights of such persons to have their privacy protected, is an integral element of any democratic society. These rights are neither absolute nor is one older than the other. In this context, the elements important for the protection of privacy are professional standards in reporting, respect for the principles of regulation and self-regulation, and respect for the right of reply. In accordance with Recommendation (2004)16 of the Committee of Ministers of the Council of Europe on the right of reply in the new media, it is absolutely relevant in the context of reporting on private life, since it provides the possibility to publish promptly any denials of disputed information. Inciting violence and invasion of privacy by the media allows regulation by the states through introduction of formalities, conditions, restrictions or penalties. Of course, the restrictions must not go beyond what is necessary in a democratic society and beyond the legitimate aim.

For example, in two cases in Germany concerning the royal family of Monaco, Von Hannover v Germany from 2004 and (no. 2) 12 2012, the criteria to be taken into account when there is a conflict of the right to freedom of expression and privacy are defined in detail. Namely, this was a case of a series of photographs of Princess Caroline of Monaco, where she is shown riding horses, skiing and stumbling on something on a private beach. These photographs were published in many journals in Germany. Stressing the importance of freedom of expression, the court stated the following: "in the cases in which the Court has had to balance the protection of private life against the freedom of expres- sion it has always stressed the contribution made by photos or articles in the press to a debate of general interest".

Of course, public figures should be subject to the public interest test, i.e. that they enjoy a lower level of privacy protection, as the European Court stated: "It would be fatal for freedom of expression in the sphere of politics if public figures could censor the press and the public debate in the name of their personality rights".

Political journalism may even contain, according to the European Court, a certain "degree of exaggeration or even provocation" (Prager and Oberschlick v. Austria no. 15974/90 25 April 1995). The focus of this topic of protection of (overall) privacy may be as stated by the European Court of Human Rights "on the issue of whether disclosure is in the public interest, and not on whether the public is interested'. As regards ordinary people, the media should have special responsibility and act professionally in situations where people are in grief, shock...

The media must also take due account when interviewing individuals or about the circumstances that directly affect the state of shock, grief, etc. the individual has suf- fered. In this context, one needs to be particularly sensitive to children when, for example, taking their statements in such situations. Ethical responsibility must be above the interest to inform the public through the child's statements. Professional balance, ethics and the public interest should also be kept in mind when publishing details of the private life of a child whose parents hold public office in the society. 
That privacy is threatened from several aspects in the global corporate system is proven by increasingly widespread examples of banks and insurance companies (especially in countries in transition), i.e. their practice of requiring their clients to provide their health records to be used in the procedures of (not) granting loans and effecting insurance policies. Moreover, there are examples where, in addition to the medical records, banks require of their clients a certificate of acute conditions, i.e. the degree of life-threat.

\section{OVERVIEW OF INTERNATIONAL STANDARDS IN PROTECTION}

\subsection{European Convention on Human Rights}

a) In accordance with this Convention and the well-known Article 10 as a guarantee of the freedom of expression "everyone has the right to freedom of reporting". This right includes "freedom to hold opinions and to receive and impart information and ideas without interference by public authority and regardless of frontiers". This article that provides specific guarantees, the right is given to an individual citizen, and not to institutions that provide the right to freedom of expression, such as the press and radio broadcasting. Article 8 of the Convention states that "everyone has the right to respect for his private and family life, his home and his correspondence". There are, of course, exceptions but they must be "in accordance with the law and necessary in a democratic society". The right to privacy may be violated if it is in the "interests of national security, public safety or the economic well-being of the country, for the prevention of disorder or crime, for the protection of health or morals, or for the protection of the rights and freedoms of others".

b) However, since the exercise of these freedoms entails duties and responsibilities, this Convention does not provide for unlimited freedom of the press. Because "the exercise of these freedoms, since it carries with it duties and responsibilities, may be subject to such formalities, conditions, restrictions or penalties as are prescribed by law and are necessary in a democratic society". As referred to in Article 8, all restrictions of this right must be either

- In the interests of national security, territorial integrity or public safety

- For the prevention of disorder or crime, for the protection of health or morals

- For the protection of the reputation or rights of others, for preventing the disclosure of information received in confidence,

- For maintaining the authority and impartiality of the judiciary.

As one of the fundamental civil and political rights and freedoms, the right to information is supported by the practice of the Court of Human Rights and the European Commission under Article 10 of the European Convention on Human Rights 
and Freedoms and is recognized under Article 9 of the European Convention on Transfrontier Television as well as in all democratic constitutions.

\subsection{Universal Declaration of Human Rights}

One of the rights directly connected with the journalistic profession is the right to privacy. Under Article 12 of the Universal Declaration of Human Rights it is stated that "no one shall be subjected to arbitrary interference with his privacy, family, home or correspondence, nor to attacks upon his honour and reputation. Everyone has the right to the protection of the law against such interference or attacks".

Article 17 of the International Covenant on Civil and Political Rights also states that "no one shall be subjected to arbitrary or unlawful interference with his private life"...

The right to privacy, guaranteed under Article 8 of the European Convention on Human Rights, was defined by the Parliamentary Assembly of the Council of Europe in the Declaration on Mass Communication Media and Human Rights, contained within Resolution no. 428 (1970), as "the right to live one's own life with a minimum of interference". Bearing in mind the new communication technologies, Resolution no. 1165 (1998) considers that this definition should be expanded so that it includes the right to control one's own data.

\subsection{Parliamentary Assembly Resolution 1165 on the right to privacy}

It is often in the name of a one-sided interpretation of the right to freedom of expression, which is guaranteed in Article 10 of the European Convention on Human Rights, that the media invade people's privacy, claiming that their readers are entitled to know everything about public figures.

Certain facts relating to the private lives of public figures, particularly politicians, may indeed be of interest to the citizens, and it may therefore be legitimate for readers, who are also voters, to be informed of those facts.

It is therefore necessary to find a way of balancing the exercise of two fundamental rights, both of which are guaranteed in the European Convention on Human Rights: the right to respect for one's private life and the right to freedom of expression.

\section{CONCLUSION}

Privacy is today perhaps more than ever in the history of civilization threatened, unprotected and left on the sidelines of the globocentric protection of human rights culture. There is an essential question of what is today the aim of the journal- 
ism's mission: to contribute to the public debate - facts and dialogue in the public interest, or to invade arbitrarily the privacy and cause a context that generates an atmosphere of distrust, arrogance of the media and encouraging intolerance of a larger social scale.

Sporadic cases and plural voices of protection are only incidental phenomenology that cannot essentially be a substitute for the predominance of profit-driven tabloid journalism. In addition, the information age and the hyper production of "smart" platforms have further crippled the legal instruments for the protection of the individual. It is obvious that, in this unequal struggle, spectacle prevails over the traditional mannerism of long outdated educational and informational aspect of the media. Taking contents uncritically and distributing them at a large scale have become a problem and a challenge for the global media culture, or more precisely for consumers of such culture.

\section{LITERATURE}

Mendel, T. (2014), Freedom of Expression: A Guide to the Interpretation and Meaning of Article 10 of the European Convention on Human Rights and its context, Council of Europe Office in Belgrade.

\section{International documents}

European Convention on Human Rights

Universal Declaration of Human Rights

Parlamentary Assembly Resolution 1165 on the right to privacy

Société Prisma Presse v. France (application no. 66910/01 and 71612/01)

\section{Case law}

Tarsasah a Szabadsagjogokert v Hungary, decision of 14 April 2009, 37-

Mosley v. the United Kingdom, decision of 10 May 2011114

Von Hannover v. Germany, 2004, item 60

Markt Intern Verlag GmbH and Klaus Beermann v. Germany, 1989, p. 35

Prager and Oberschlick v. Austria no. 15974/90 25 April 1995 